\title{
La Catedral de Málaga. Implicaciones de una posible actuación en la cubierta
}

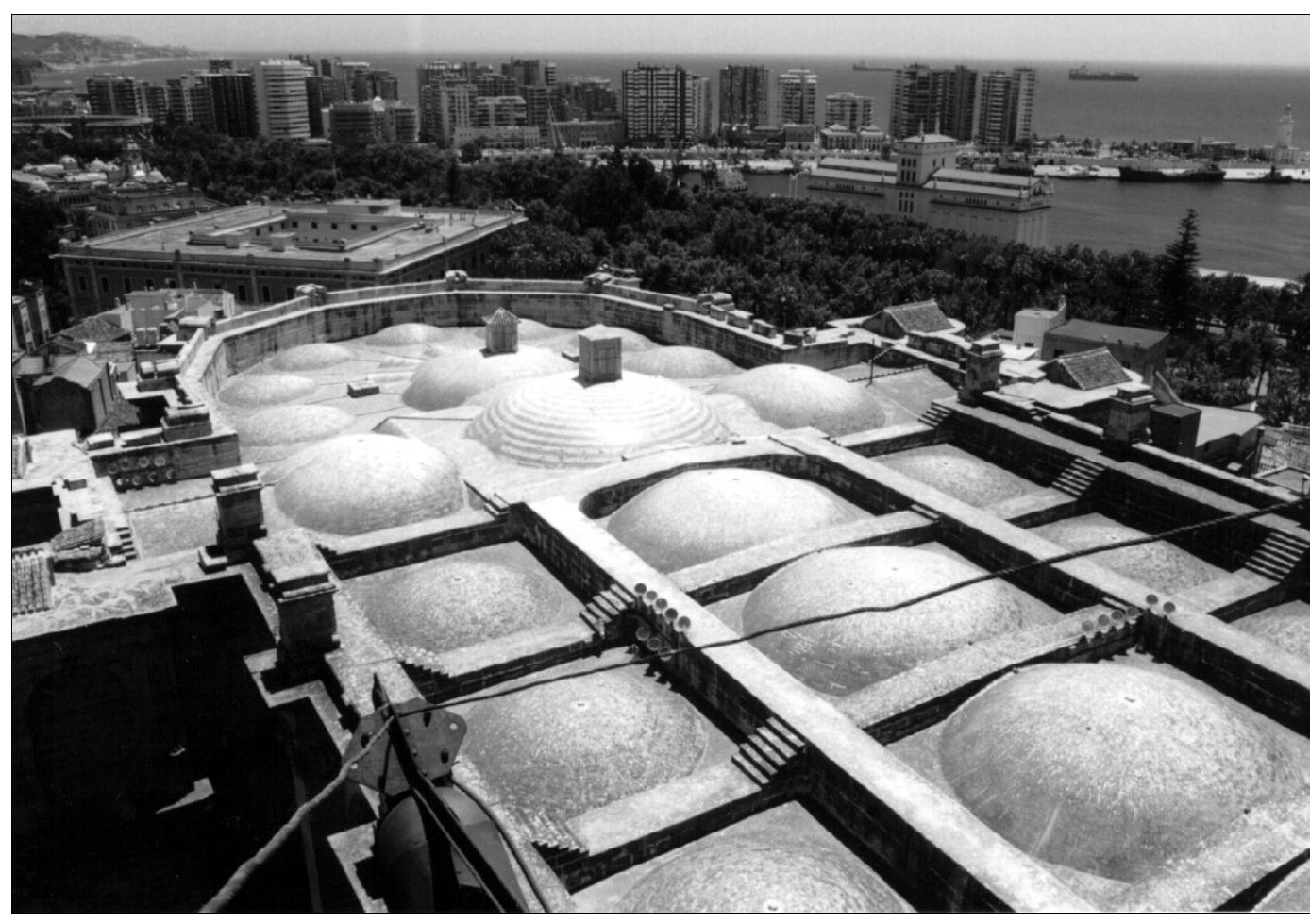

Pedro Rodríguez Pérez Antonio Tejedor Cabrera Arquitectos

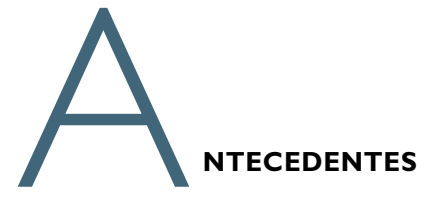

Este artículo tiene su origen en el informe-dictamen que sus autores realizaron para el Centro de Intervenciones del I.A.P.H. a petición de la Delegación Provincial de Málaga de la Consejería de Cultura en julio de 1997. Las cuestiones más importantes recogidas en la solicitud de la Delegación se concretaban en la preocupación por las implicaciones estructurales, constructivas y formales de un proyecto de intervención en la cubierta de la Catedral de Málaga y en la petición de sugerencias para su Plan Director.

La Catedral de Málaga es un edificio históricamente bien estudiado, como se recoge en los trabajos de $D^{a}$ Rosario Camacho Martínez, quien ha redactado el Resumen Histórico que encabeza la Memoria del reciente Proyecto de Cubiertas de Mendiola y Ramos, con un vasto y oportuno apéndice documental, y en los de otros especialistas, como D. Lorenzo Pérez del Campo y D. Luis Romero de TorresI. 

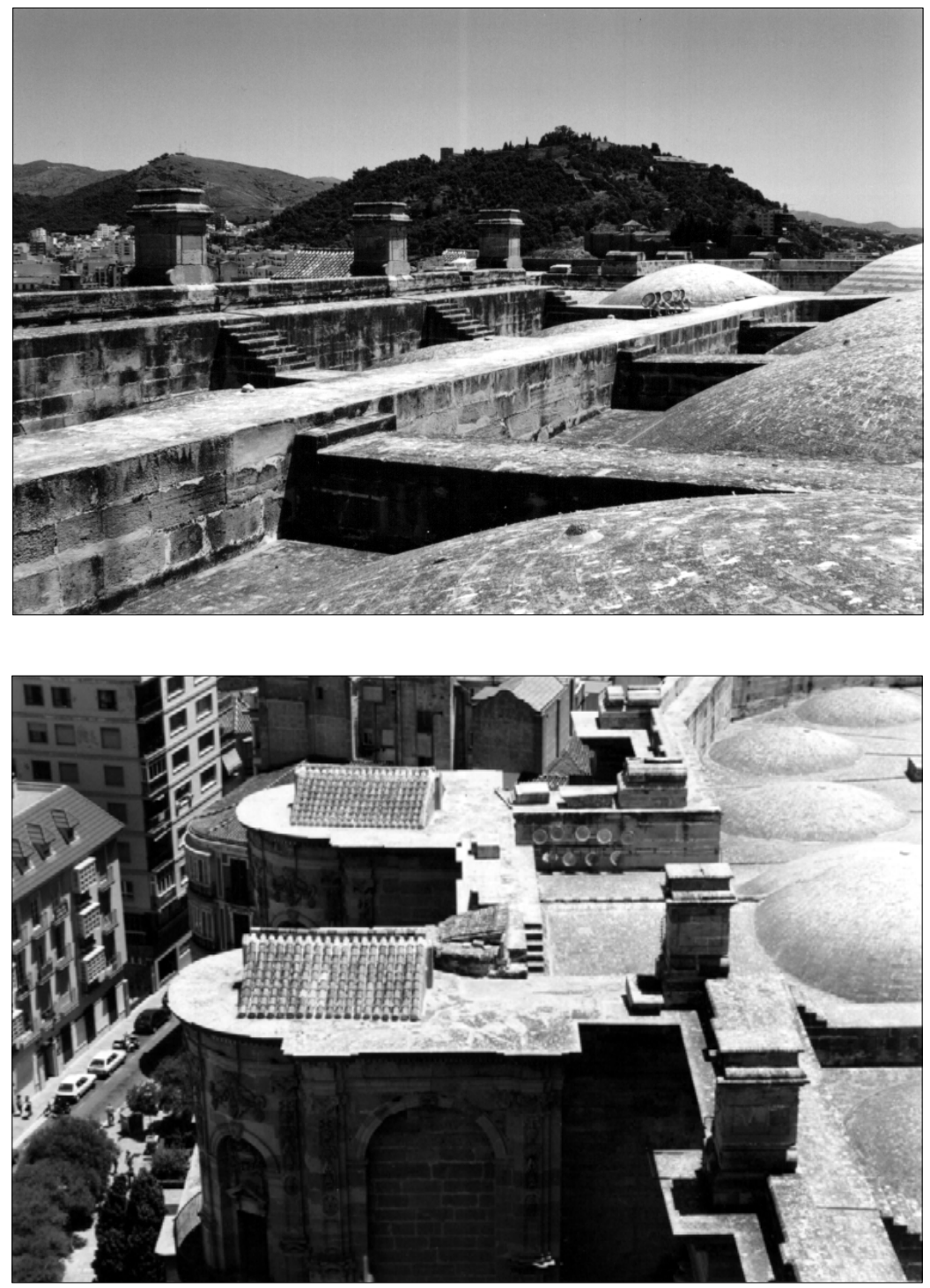

I. Cubiertas y pretiles de la nave Norte desde la central.

2. Cubiertas. La puerta Norte
Por ello, vamos a omitir aquí mayores detalles sobre su devenir, limitándonos a remitir al lector a las obras de estos autores.

El resultado de la azarosa construcción del templo mayor malagueño, aparece hoy como una notabilísima edificación de tres naves longitudinales, bordeadas de otra de capillas, que abren a las laterales, las cuales rodean a su vez a la principal dando lugar a una girola, muy esbelta, por la enorme altura del conjunto, singularmente elevado a partir de las cornisas que coronan los soportes, y por la total igualdad de altura entre sus bóvedas, sobre las que solo destaca discretamente la cúpula del transepto.

A pesar de la separación temporal y los cambios de circunstancias, criterios y posibilidades económicas de las distintas fases proyectuales y constructivas, el conjunto aparenta una fuerte unidad, con gran armonía espacial interna, y clara articulación volumétrica exterior, cuya simetría de traza solo se trunca por la inconclusión de las partes superiores, principalmente de la torre Sur, pero también del frontón de la fachada principal, y de los pedestales que, no en todo el perímetro de las cubiertas altas, como estaba pensado y dibuja- do, esperan aún los flameros de José de Bada, o los colosos de Antonio Ramos.

Lo que nunca llegaron a dibujar los maestros mencionados, fue cubierta alguna que sobresaliera de los citados remates. Una observación ligera de las secciones que nos dejaron grabadas, permite entender la idea de aterrazamiento (menos abrupto que el actual, desde luego) que parecía coronar sus visiones del templo.

\section{RECONOCIMIENTOS DE LAS CUBIERTAS}

Como complemento del estudio de los documentos disponibles, alguno de los cuales se tratará extensamente a lo largo de este artículo, se realizó una visita al monumento el día 13 de junio, acompañados de $D^{a}$. María Morente del Monte, Jefa del Departamento de Protección y de las Instituciones del Patrimonio, y $D^{a}$. Ana Rojo Montijano, arquitecta, ambas de la Delegación Provincial de Cultura de Málaga, los arquitectos D. Rafael J. Gómez Martín y D. Tristán Martínez Auladell, autores del Diagnóstico Previo y de varios proyectos de intervención en la Catedral y el aparejador de fábrica D. Fernando Ramos de Rivas. En esta visita se recorrió el interior del templo y, con mayor detenimiento, las cubiertas altas, las laterales septentrionales entre la nave transversal y los pies del edificio y la torre Norte.

La inspección directa del lugar permitió corroborar todos los asertos sobre el mismo que se recogen en la documentación histórica de la Catedral, comprobándose el forzado remate sin fondos económicos de las obras, que parecen estar abandonadas ayer mismo, con bloques de piedra descargados de cualquier forma, no todos asentados ni trabados ni completos, en lo que a los pedestales de los remates barrocos se refiere.

La cubierta que ha llegado hasta nosotros se resuelve con un sistema de evacuación de aguas pluviales muy complejo, sobre todo en la parte barroca, comunicando mediante mechinales los recuadros entre muretes en cuyos centros emergen los lomos de las bóvedas. Los mechinales practicados en el pretil perimetral desembocan en gárgolas y bajantes que discurren empotrados en los machones de las fachadas. A simple vista, es difícil afirmar si estaban preparadas para ser cubiertas por un tejado como el planteado por Ventura Rodríguez solo dieciocho años antes de la paralización de las obras, o para ser generosamente trasdosadas dando lugar a una terraza más continua y menos conflictiva².

Menos forzada es la solución de cubiertas de la cabecera renacentista que, sin embargo, presenta problemas a la hora de desaguar los extremos de la nave transversal, mediante gárgolas que vierten tangentes a los muros longitudinales.

Aunque el interior del templo presenta abundantes señales de humedad en pechinas y en tímpanos, la fecha y la hora de la visita a las cubiertas no ha sido la más adecuada para observar embalses de agua, filtraciones, salideros de bajantes por las juntas y otras tan- 
tas de las anomalías que nos cuentan documentos más o menos antiguos y testigos oculares.

A los evidentes y graves problemas de descamación y alveolización de las piedras calizas de las encimeras y pedestales aludidos más arriba, hay que sumar eflorescencias en varios paramentos verticales de los muretes de arenisca perimetrales e intermedios, pero sin más transcendencia que las vistas en otros muchos edificios de características similares, no difícilmente subsanables con intervenciones de pura albañilería y mantenimiento clásicos.

Se aprecian deterioros superficiales en piezas de material cerámico, puntos débiles en las uniones entre bóvedas y terracillas adyacentes cuyas pendientes y drenajes superficiales son a menudo forzados así como la falta absoluta de impermeabilización en las coronaciones de todos los muros y pretiles.

También hemos podido observar los efectos de la plaga actual de gaviotas con su secuela de guano y despojos que constituye, en nuestra opinión, la amenaza más seria contra la evacuación de las aguas de la cubierta actual, pues son perfectamente capaces de obstruir los bajantes con enorme facilidad y rapidez, si lo anterior se combina con la aportación de plumas y otros materiales de los nidos que allí mismo están haciendo.

El reportaje fotográfico realizado en la visita que comentamos recoge vistas tanto desde las cubiertas como desde la torre de la Catedral y otros puntos exteriores que son miradores públicos privilegiados de la ciudad. De él se han extraído algunas imágenes que ilustran estas líneas.

\section{ANÁLISIS DEL PROYECTO DE CUBIERTA DE MENDIOLA Y RAMOS}

El "Proyecto de Cubierta de la S.I. Catedral de Málaga" de D. Álvaro Mendiola y D. Fernando Ramos se inserta en la campaña "Salvemos la Catedral 199697". Este trabajo se interpreta aquí como "Proyecto Básico y de Ejecución de Cubierta" ya que su finalidad es la intervención inmediata en la Catedral para subsanar el problema de filtraciones del agua de lluvia en sus cubiertas. Los autores proponen una versión del proyecto de tejado de junio de 1.764 debido a Ventura Rodríguez, cuyos dibujos recogen junto a una transcripción de sus leyendas al castellano moderno.

\section{Solución formal e impacto visual}

Como la solución dieciochesca en la que el autor del proyecto se inspira, ésta tiene la virtud arquitectónica de acabar constructivamente el edificio, rematándolo de una forma geométrica simple, y dotándolo sobre el papel de la cobertura que nunca llegó a tener. Una cubierta de este tipo garantizaría, de estar bien resuelta, la máxima seguridad para la conservación de sus bóvedas, hoy escasamente protegidas por unos desa-
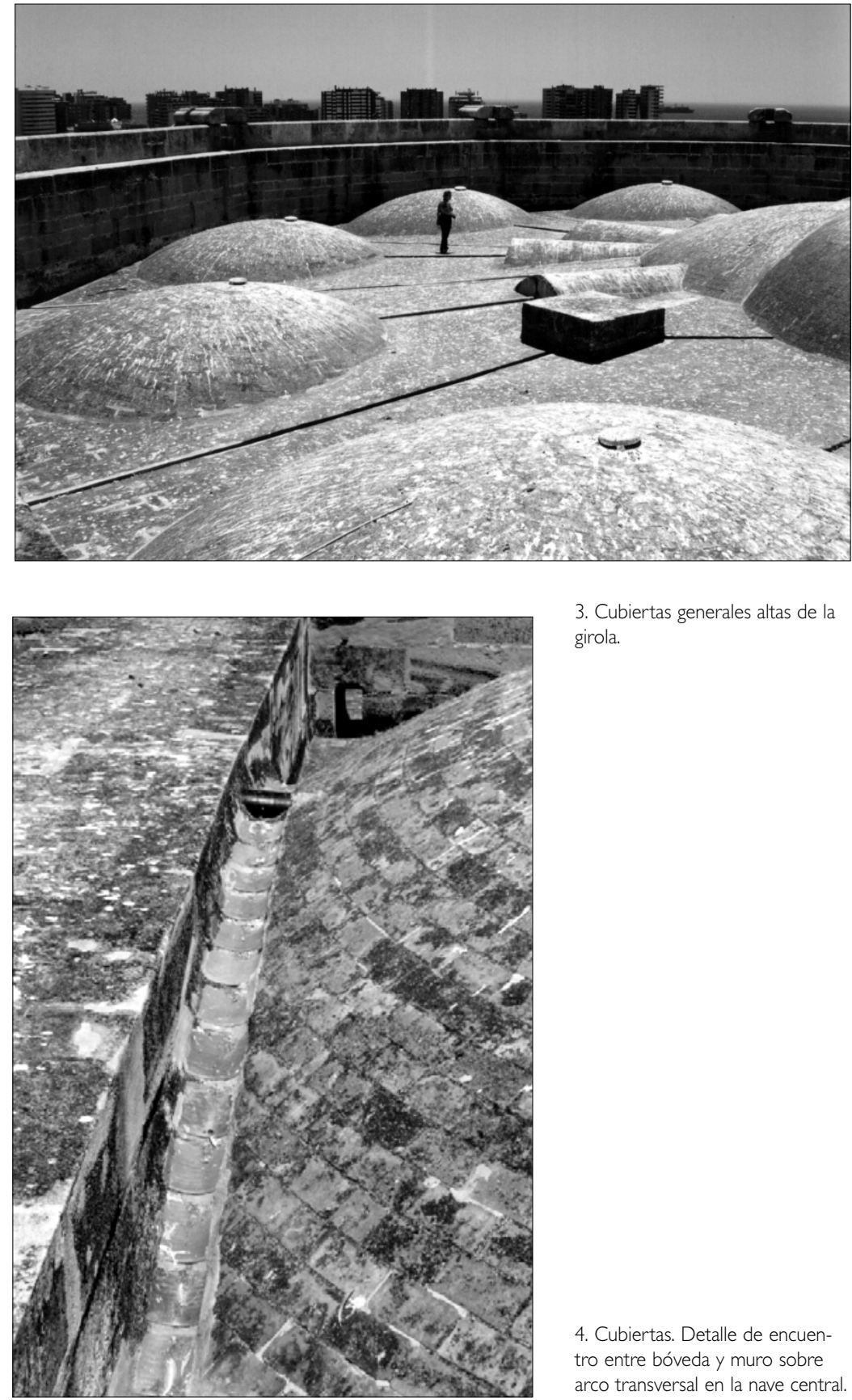

3. Cubiertas generales altas de la girola.

4. Cubiertas. Detalle de encuentro entre bóveda y muro sobre arco transversal en la nave central. fortunados trasdosados fruto de la penuria económica de todos conocida, que tan mal resultado han dado desde su creación hasta hoy.

Desde el punto de vista formal, tiene a su favor, respecto del proyecto de Ventura Rodríguez, la mayor discreción en la formalización de un faldón hacia el muro de Poniente, con lo que se evita la realización del potente frontón, obligado en la solución de 1.764, (y solo levemente esbozado por su autor) cuya realización hoy sería más que cuestionable.

No obstante lo anterior, y dada la importancia de los aspectos puramente visuales, el proyecto no aporta un estudio de la imagen que la cubierta propuesta podría tener desde los lugares públicos más frecuentados de la ciudad, a modo de análisis de su impacto visual 


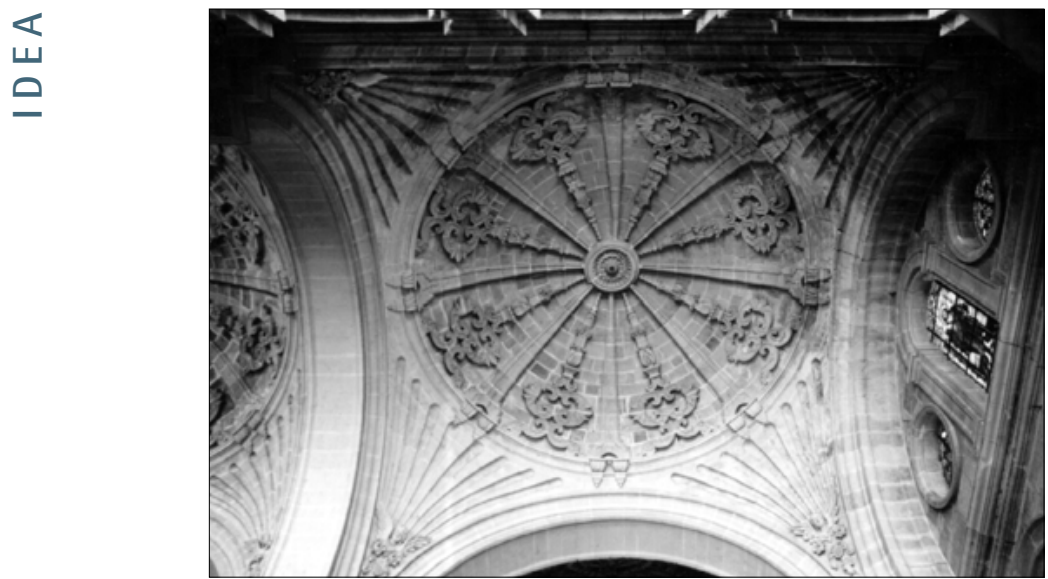

5. Interior. Bóveda final de la nave del Evangelio

6. Interior. Bóvedas y pilares desde el rincón Noroeste de la cornisa perimetral.

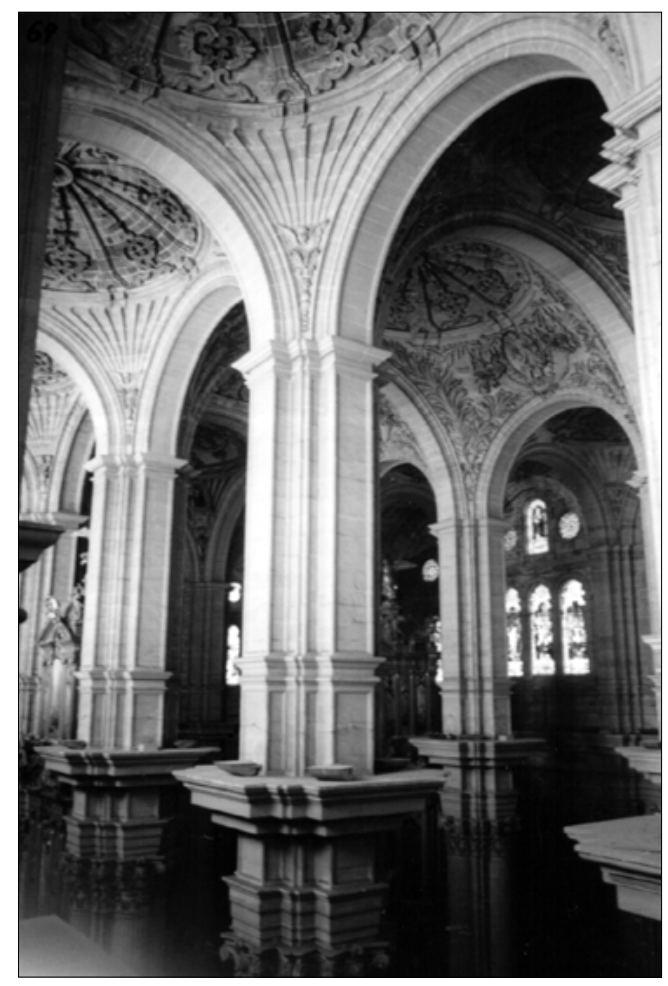

urbano, a base de pares de fotografías con montajes adecuados, o por cualquiera de los procedimientos informáticos hoy disponibles.

\section{Aspectos documentales}

Desde el punto de vista documental, la definición del proyecto actual, y quizás a causa de la falta de tiempo, con que se haya tenido que redactar no permite de ningún modo una puesta en obra con las mínimas garantías exigibles a una intervención de esta naturaleza.

A este respecto resultan especialmente insuficientes tanto el Pliego de Condiciones Técnicas, de una sola página, como el Presupuesto, de dos, lo que contrasta con la extensa y profunda introducción histórica de la profesora $D^{a}$. Rosario Camacho. Por otro lado, la memoria es muy escueta, aunque cumple su función descriptiva complementaria de los planos, si bien obvia cualquier referencia a alternativas, siquiera geométricas o dimensionales, del tipo elegido.

Por otra parte, la incoherencia entre la planta y los alzados longitudinales, en los que no se reflejan los testeros de los tejados de la nave transversal en su tamaño real (unos dos metros más altos que los dibujados en éstos) así como los errores en los encuentros entre ellos, el de la nave principal y el de la cabecera, son preocupantes.

Lo mismo cabe decir de las estructuras dibujadas en la sección longitudinal y en la planta correspondiente, tanto en esos lugares como en los encuentros de la nave transversal, y las que figuran en los planos finales, que son los respetados en los esquemas de cálculo. Nada tienen que ver unas con otras, y muchas de las cerchas dibujadas no están diseñadas ni calculadas.

\section{Solución estructural}

Estructuralmente hablando, la ausencia de tirante continuo transversal en la nave central, por impedirlo la aparición de los lomos de las bóvedas al haberse elegido un intereje tan pequeño entre cerchas (un metro), provoca la asunción de esfuerzos horizontales permanentes y variables de origen térmico, aún sin la acción del viento o del sismo, agravados por la innecesaria rigidez de la estructura en el plano vertical medio.

El apoyo casi continuo de las cerchas en los muros longitudinales sobre los arcos que separan las naves laterales de la central, provoca una asimetría permanente de cargas entre éstos y los transversales que, aún siendo relativamente pequeña, no es beneficiosa y se podía haber evitado.

En la cabecera, en los pies y en los encuentros con la nave transversal, las incoherencias y omisiones antes reseñadas impiden hacer una valoración de las consecuencias estructurales que para las bóvedas y arcos tendría la puesta en obra de lo proyectado.

El propio cálculo necesitaría ser aclarado en lo concerniente a los vínculos elegidos, algunos de los cuales parecen ser nudos interiores de las nuevas estructuras, con lo que los apoyos reales de éstas sobre los elementos preexistentes se ven incomprensiblemente aligerados de carga.

Por otra parte, no parece aconsejable despreciar las oscilaciones térmicas en una estructura como la diseñada, sin haber aislado convenientemente la cubierta, y esa carga térmica debería calcularse para el salto diario y estacional característico de un período de retorno congruente con la durabilidad que debe asignarse a tan singular, grande y difícilmente conservable estructura.

Algo parecido puede comentarse sobre la acción sísmica, pues aunque probablemente no sea crítica en esta estructura, es importante ver los efectos inducidos por ella en la vieja fábrica. 
Los elementos secundarios de la estructura, tales como cerchas menores, correas, etc., deben ser calculados, así como las placas de sustento de las tejas, cuya sujeción (si se mantuviesen en el proyecto definitivo) debería ser objeto de ensayos previos y de control.

En todo caso, debería de acompañarse un resumen de las tensiones previsibles en la fábrica antigua, en los puntos de apoyo de la nueva estructura, cuyo diseño específico parece haber sido tomado muy a la ligera.

\section{Aspectos funcionales}

No se explica en ninguna parte del proyecto el modo de acceder al enorme camaranchón que se cobija bajo la nueva cubierta, pues las dos escaleras de los pies no se conectan en ningún punto con él, ni aparece dibujada ni citada trampilla o buhardilla alguna.

El diseño de la estructura, con cerchas trianguladas dispuestas cada metro, da lugar a una auténtica maraña de barras que dificultan innecesariamente la estancia y el paso entre bóvedas laterales, a pesar de que bajo la hilera se lleguen a alcanzar más de ocho metros de altura, con la consiguiente dificultad para su propio mantenimiento.

La ventilación propuesta para el recinto parece claramente insuficiente, pues según lo dibujado y referido en memoria, se tendría Im2 de hueco por cada $38 \mathrm{Im}^{2}$ de planta, complementado, al parecer, con tejas de ventilación sólo citadas de paso.

Por lo descrito gráfica y textualmente en el proyecto que comentamos, la oscuridad en la cámara bajo cubiertas, que se pretende útil para las labores de restauración y conservación de las bóvedas inferiores, será total incluso a plena luz del día, sin que se haya dispuesto ningún lucernario ni instalación de alumbrado sustitutivo de la luz natural.

La disposición del canalón perimetral, con la dimensión que aparece en los planos finales dedicados a los detalles constructivos, dificultaría la conservación de la propia cubierta nueva en la que, además, no se prevén ganchos ni otros dispositivos para asegurar al personal de mantenimiento.

Desde el punto de vista de la evacuación de las aguas debería incluirse un mínimo estudio de recorridos de evacuación y necesidades dimensionales que justifique las modificaciones introducidas en los bajantes, no suficientemente explicitadas en el proyecto y un cálculo de los caudales a recoger en cada vertiente y los puntos elegidos para su drenaje por nuevos o viejos bajantes que, en nuestra opinión, deberían protegerse si se reutilizan. Un aspecto interesante del diseño de desagües del canalón lo constituye la disposición de rebosaderos, si bien no se aclara con qué frecuencia se dispondrían ni cómo se recogería el agua rebosada, aunque parece caer libremente por perforaciones hechas a media altura de los petos perimetrales, por encima de las cornisas superiores.

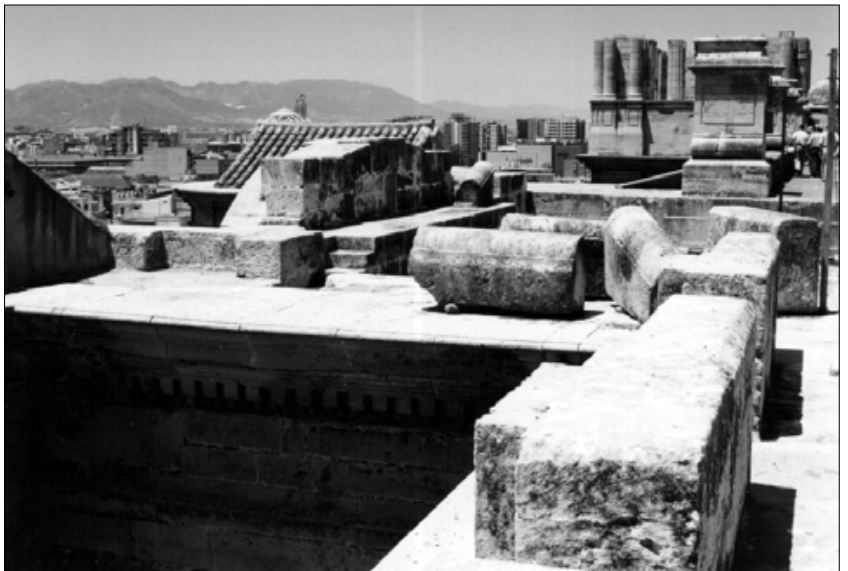

$\varangle$ 山

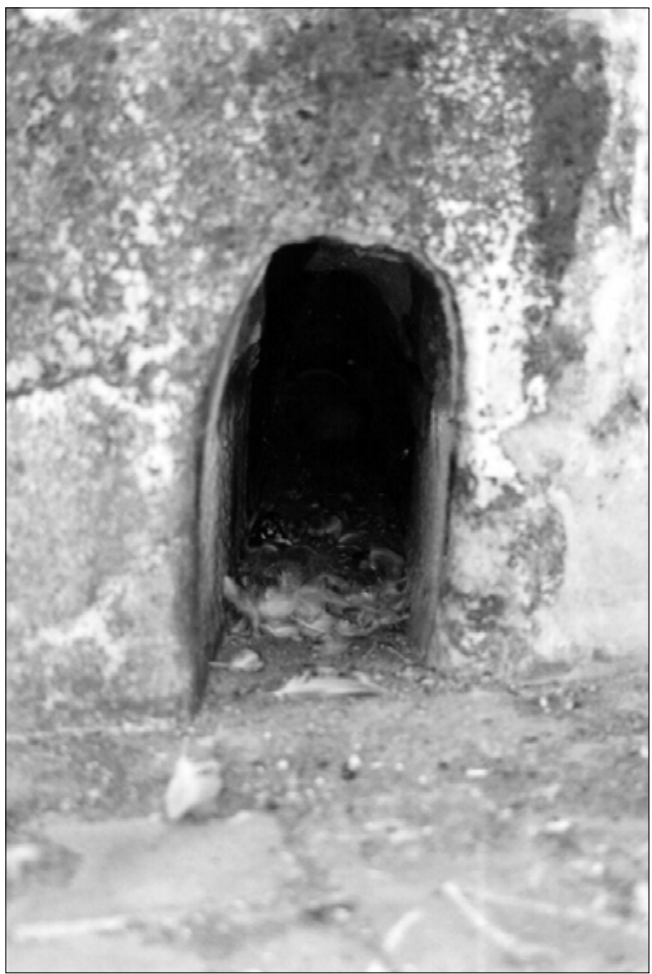

7. Cubiertas. Sillares sueltos en la esquina Sureste del transepto.

8. Cubiertas. Restos de plumas en la embocadura de un bajante.
El proyecto no alcanza al conjunto de las cubiertas de la Catedral al prescindir del análisis, diagnóstico y propuestas de intervención sobre las terrazas bajas, en las que vierten en primera instancia los bajantes y gárgolas de la cubierta superior. Tampoco contempla el drenaje de tales terrazas a la red municipal de alcantarillado o a la vía pública.

\section{Aspectos constructivos}

El material base de la estructura (acero galvanizado) parece uno de los más adecuados de entre los posibles en nuestro entorno comercial, aunque se debería haber planteado alternativamente el uso de otros igualmente interesantes. Para el elegido, es preferible que las uniones de piezas en obra (que no recordamos haber visto definidas en la documentación) se realicen mediante tornillos y no con soldadura, para evitar la desprotección galvánica y facilitar el montaje. 


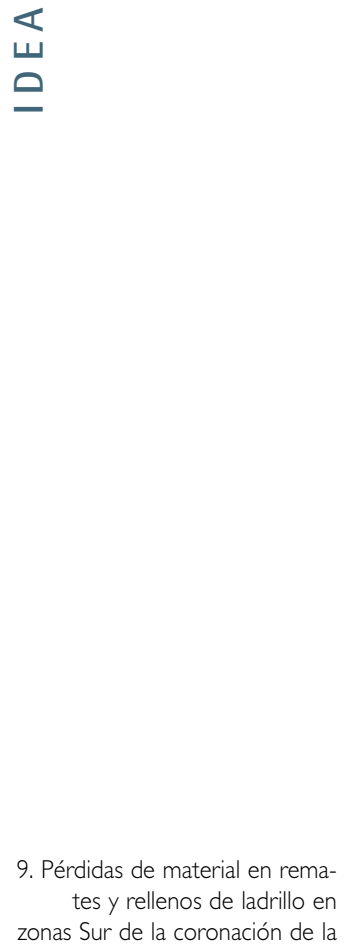
zonas Sur de la coronación de la fachada principal.

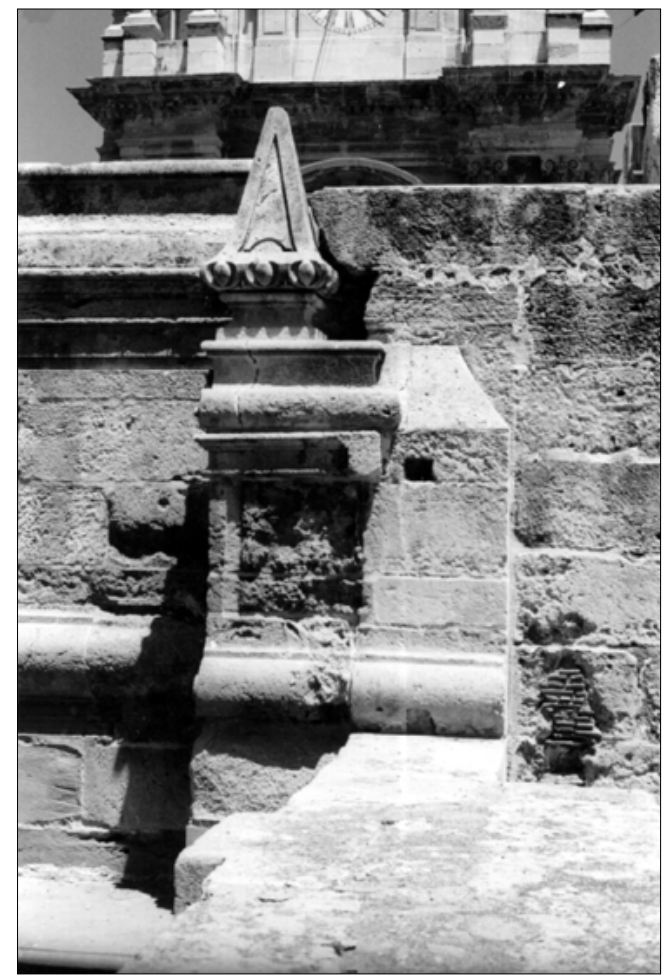

Desde el punto de vista de la realización de la obra, debería explicarse muy bien cómo van a montarse los elementos y subconjuntos estructurales, y qué lugar de los alrededores de la Catedral va a utilizarse como recinto de suministros, acopios, evacuación de residuos, etc, así como los recorridos y dispositivos de subida y bajada de materiales, mano de obra y equipos a las cubiertas.

\section{Obras y controles complementarios}

Llama la atención la ausencia total de descripción de operaciones de protección temporal de lo existente y de las lógicas unidades de adaptación y enlace con lo nuevo, inevitables en este tipo de intervenciones, así como disposiciones para el control del comportamiento de los elementos afectados por el nuevo régimen tensional e higrotérmico.

\section{Conclusiones}

A nuestro entender, este proyecto es negativo para la catedral de Málaga tanto por la solución de cubierta en su conjunto como por la falta de rigor en el diagnóstico y en la formulación y justificación de la solución adoptada.

No es deseable apoyar la bondad del proyecto arquitectónico sobre un bien tan relevante sólo en consideraciones formales: la similitud entre este proyecto y la cobertura de Ventura Rodríguez apenas alcanza siquiera a la disposición de los faldones de teja, como una sencilla comparación entre ambos puede transmitir.

Idea, forma y construcción deben estar ligados entre sí por una concepción global del sistema de cobertura que no prescinda del análisis de otras alternativas formales y constructivas. Por ejemplo, no son disociables los problemas de la cubierta principal de los de las terrazas laterales y de la girola, ni éstos de las soluciones de vertido final a la red de alcantarillado o a la vía pública, aspectos que el proyecto en cuestión no aborda en ningún sentido.

La formulación del documento proyectual presenta múltiples déficits que ya se han señalado. La solución presentada es precipitada e incompleta, y no evalúa el impacto visual que tendría sobre la propia catedral y su entorno. La referencia a opiniones autorizadas a favor de la cubierta de tejas no deja de ser un recurso valioso aunque precario en un documento de carácter técnico destinado a la puesta en obra de una solución que debe calibrar su propio impacto formal y constructivo.

Todo ello, sin perjuicio de la oportunidad que la propuesta de cobertura ha supuesto para acelerar los procesos en marcha sobre la Catedral de Málaga y favorecer la participación más directa de los ciudadanos en la conservación de su patrimonio histórico.

\section{EL MODELO DE INTERVENCIÓN EN LA CATEDRAL DE MÁLAGA}

En 1996 la alcaldía de Málaga puso en marcha la campaña "Salvemos la Catedral", cuyo origen estuvo en la caída de una piedra de cornisa, presentándose el Proyecto de Cubierta comentado como actuación inmediata en el marco de dicha campaña. Sin embargo, como hemos comprobado, la propuesta presentada para la cobertura de la Catedral no atiende en absoluto el problema de las cornisas, que es específico e incluso independiente en su origen y soluciones del problema de filtraciones de agua en las bóvedas, ya que las cornisas se encuentran en la actualidad por encima del primer plano de desagüe de la cubierta. Parece más oportuno, por tanto, realizar en primer lugar una campaña de reconocimiento, tratamiento y cosido de partes fracturadas o inestables de las cornisas, que podría extenderse a todas las fachadas del monumento.

Con anterioridad a la aparición del "Proyecto de Cubierta" para la Catedral de Málaga, la Consejería de Cultura viene desarrollando desde el año 1987 un conjunto de actuaciones en el marco del Plan de Catedrales de Andalucía. Entre otros aspectos se contempla en él la sistematización de las primeras actuaciones a partir del levantamiento planimétrico y del Diagnóstico Previo como estudio específico de las patologías existentes. Este Plan se inició con motivo de la formulación del primer Plan General de Bienes Culturales de Andalucía 1989-1995. De su aplicación, resultaron proyectos y actuaciones de distinta índole en las doce catedrales andaluzas por más de 3.000 millones de pesetas, correspondiendo a la Catedral de Málaga en dicho período 425, I millones, destinados al levantamiento planimétrico y a diez intervenciones de distinta entidad 3 . El nuevo Plan General de Bienes Culturales 1996-2000 prolonga el Plan de Catedrales y lo dota de mayor vigor al exigir la elaboración de un Plan Director por cada catedral, 
destinado a perfilar definitivamente las intervenciones según las prioridades y haciendo especial hincapié en la cooperación de las instituciones implicadas (Iglesia, Consejería de Cultura y Ayuntamientos) que compartirían responsabilidades y financiación.

Corresponde al Plan Director de la Catedral de Málaga esta misión primordial de sistematización y coordinación institucional. En la práctica, se concreta en la racionalización de las actuaciones en el período asignado por el Plan General de Bienes Culturales, sus plazos e inversiones, financiación y medidas de cooperación, patronazgo, etc. A largo plazo, está destinado a establecer las directrices generales que son necesarias para la conservación futura de la Catedral en un proceso concertado entre la autoridad eclesiástica y las administraciones públicas responsables, sin sorpresas o propuestas polemistas y con estudios bien documentados y ampliamente difundidos. La cuestión de la nueva cubierta de la Catedral podría ser tratada así con el rigor y la participación de las entidades implicadas que la complejidad del problema, según hemos visto, requiere.

El Plan Director de la Catedral de Málaga es absolutamente imprescindible y puede acometerse a la vista de las primeras conclusiones que aporte el Diagnóstico Previo, actualmente en su última fase de redacción. Como instrumento de valoración general del estado de conservación de la Catedral, el Diagnóstico Previo sigue siendo prioritario y debe completarse con nuevos estudios y análisis que se reseñan más adelante. Mientras se procede a su terminación por parte del equipo redactor, deben acometerse además algunas actuaciones puntuales urgentes:

\section{INTERVENCIONES CON CARÁCTER URGENTE}

I. Todos los deterioros observados en la visita al lugar, salvo los producidos por las gaviotas, pueden resolverse provisionalmente con tratamientos de limpieza, hidrorrepelentes y consolidantes, y con la disposición de morteros de revestimiento permeables al vapor de agua, amén de renovar las solerías que presenten una permeabilidad inaceptable, demostrada mediante ensayos. Estas actuaciones deben extenderse a todas las partes y elementos de las cubiertas, bóvedas y terrazas, pretiles y remates, bajantes y gárgolas.

2. Se debe proceder inmediatamente a la fijación y consolidación de las cornisas mediante las actuaciones de cosido, sustitución, reposición, etc. de los elementos salientes que presenten disyunciones y riesgo de desprendimiento. Una inspección más minuciosa puede aconsejar la disposición de redes provisionales de protección, tanto en el perímetro como en el interior de la Catedral, frente a caídas de pequeños fragmentos de piedra.

3. Consideramos urgentes las actuaciones de limpieza de guano y desperdicios de gaviotas. La eliminación de los nidos que ya se han generado, la disposición de redes sobre las bóvedas y la aplicación de las medidas propuestas por la A.M.A. para desplazar a las gaviotas también se consideran prioritarias.

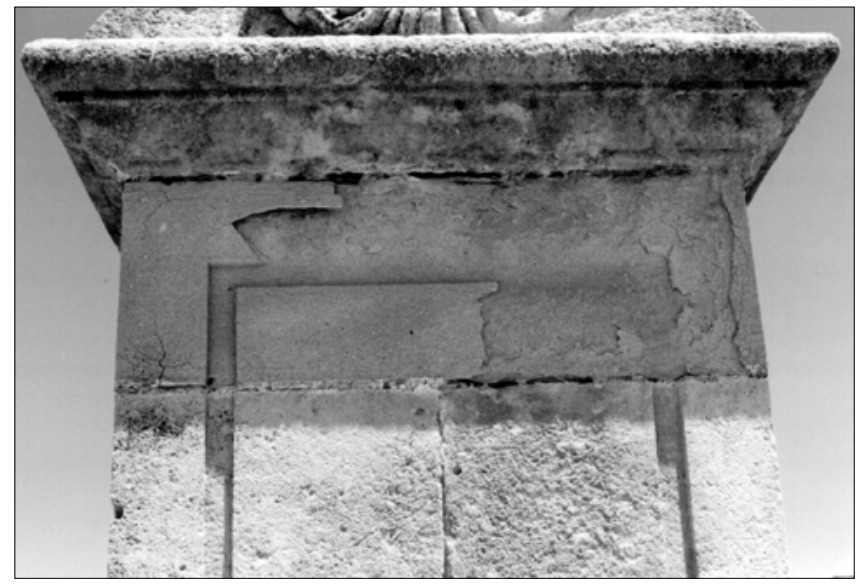

$\varangle$

\section{FORMULACION DE ESTUDIOS Y ANÁLISIS PREVIOS} tales de la nave Sur.

Se considera necesario para dilucidar sobre la optimización de una posible cubierta la formulación de los siguientes estudios complementarios de los existentes:

I. Análisis comparado de soluciones similares en las catedrales de Andalucía (p.e. las catedrales de Granada, Jaén, Guadix, Baeza) y en otros contextos geográficos y climáticos.

2. Modelización detallada de la topografía de la cubierta y comportamiento actual del sistema de recogida y evacuación de aguas pluviales.

3. Reconocimiento sistemático con utilización de técnicas de medición directa de humedades (protímetro, medición de humedad en laboratorio sobre probetastestigo extraídas In situ, etc) complementados si es posible con técnicas de medición indirecta (termografía). Grafiado sobre planimetría adecuada de las filtraciones, niveles de humedad y deterioros en bóvedas.

4. Estudios constructivo-estructurales de la fábrica en su conjunto y de sus partes: Aproximación a las cargas, esfuerzos y tensiones medias actuales, incluso como prevención de problemas futuros.

5. Análisis de alternativas formales, tipológicas y constructivas para la cobertura de la Catedral de Málaga. Existe una gama extensa de soluciones que van desde la impermeabilización de la superficie de la cubierta actual (mínima posible) a la superposición de una cobertura autónoma (duplicación de la cubierta) pasando por soluciones tradicionales (armadura y teja) y tecnológicamente más actuales (ligeras, planas, curvas, etc.). Este análisis debe incluir el estudio del impacto visual de las alternativas más apreciadas, con simulación por ordenador, desde ubicaciones próximas y lejanas.

6. Valoración comparativa de estas alternativas desde el punto de vista formal, estructural y económico.

\section{OBSERVACIONES FINALES}

A modo de resumen cabe insistir en las siguientes consideraciones: 

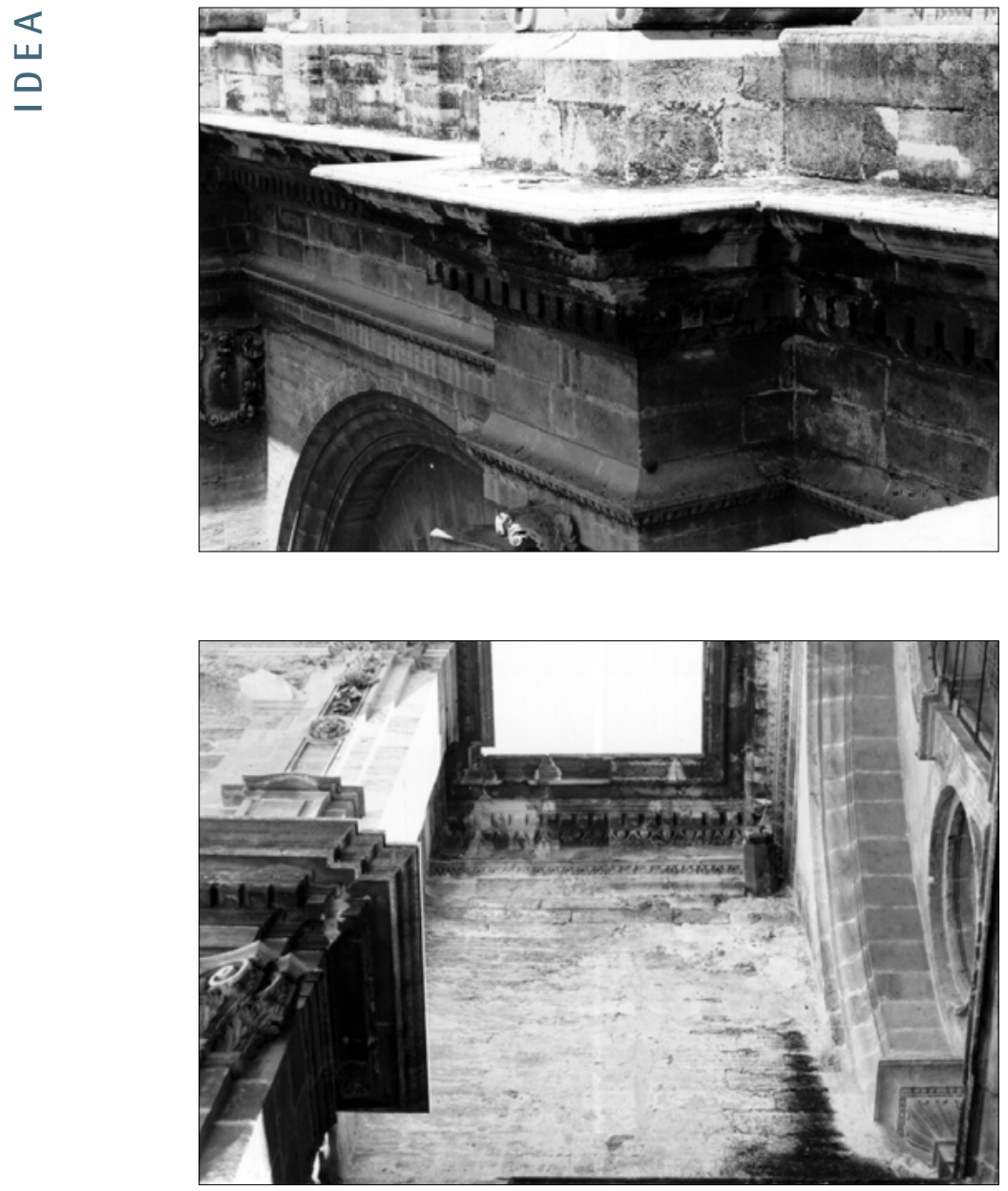

II. Fachadas Sur. Cornisas mostrando las costras originadas por la polución atmosférica.

12. Fachadas. Cornisas de la cara occidental del brazo Norte del transepto. Gárgola tangente a la fachada Norte.
I. La configuración actual de las cubiertas y sus sistemas de drenaje no garantizan a largo plazo una respuesta adecuada a las necesidades de impermeabilización y conservación continuada de la Catedral de Málaga.

2. El "Proyecto de Cubierta" de Mendiola-Ramos se considera negativo para la Catedral al no abordar el problema de la cobertura y drenaje ni de forma global ni detallada.

3. Corresponde al Plan Director de la Catedral de Málaga establecer una visión global de los problemas de la Iglesia Mayor y una metodología de trabajo a medio plazo que incida especialmente sobre las cubiertas. El Plan Director establecerá también las medidas a largo plazo, entre las que sobresalen las destinadas al mantenimiento ordinario del monumento con una asignación de recursos garantizada.

4. Mientras se perfila el Plan Director, deben realizarse con carácter urgente actuaciones de dos tipos: reparaciones de las cornisas y cubiertas, y protección de éstas frente a la agresiva acción de las gaviotas. Además, la última fase del Diagnóstico Previo debería incorporar los estudios y análisis que complementen los ya efectuados, entre los que destaca el análisis de las alternativas de cobertura, estimándose como deseable un plazo de seis meses para su finalización.
5. No es posible pronunciarse sobre la solución "definitiva" de cubierta sin los estudios anteriores. Esta línea de investigación propuesta adquiere su sentido final con la formulación de un proyecto arquitectónico, capaz de ofrecer soluciones creativas $y$, a la vez, técnicamente rigurosas y viables.

6. El modelo de intervención en la Catedral de Málaga queda perfilado así con tres ámbitos de trabajo complementarios que suponen en la práctica tres escalas temporales de acción: la intervención inmediata o urgente, la línea de investigación que se concreta en el documento final de Diagnóstico Previo y el Plan Director.

\section{ANEXOS}

\section{A. Consideraciones generales sobre una posible cubierta}

Sin perjuicio de la necesaria realización de los estudios descritos en el apartado anterior, se avanzan las siguientes consideraciones generales con el fin de contestar a la demanda de la Delegación de Málaga de la Consejería de Cultura:

I. Es deseable que la solución de cubierta que se elija, en su caso, sea ligera, aislada térmicamente, de estructura isostática, simple y diáfana, con apoyos sobre los pilares, mejor que sobre los arcos, al menos en el interior, y con atirantados inferiores que eviten en lo posible esfuerzos horizontales a la construcción antigua. En este caso, el cálculo de la estructura deberá ser cuidadoso en su planteamiento, y su resolución constructiva matizada en todo aquello que se refiera a la transferencia de las nuevas cargas a lo ya construido.

2. Debería permitir el trabajo de restauración de las bóvedas de forma pausada, hacerlo agradable, seguro y con buena visibilidad a bajo costo. Además, debería permitir el acceso fácil, la ventilación y la iluminación suficientes, mejor naturales. Además, no debería constituir en sí misma un problema de mantenimiento importante, resultando accesible en altura y fácil de reparar, sin recurrir a técnicas o materiales de difícil consecución.

Esto es especialmente recomendable si ha habido, como es el caso, reiteradas humectaciones de piedra y alcatifas, que más tarde o más temprano deberán levantarse con la continuidad o discontinuidad que permitan, una vez más, los fondos disponibles, y airearse -sin riesgo de humectación- durante un tiempo razonable, si no se quiere que los tratamientos químicos (que de todos modos habrá que dar a las piedras dañadas por una o las dos caras) sean rechazados una y otra vez.

3. El sistema de evacuación de aguas debería estar previsto desde el principio del proyecto, incluyéndose la definición técnica y económica de las opera- 
ciones restauradoras y de complementación de las salidas existentes.

4. En todo caso, la solución de cubrir las bóvedas no exime de tratar la piedra de pretiles y pedestales exteriores, con los productos químicos aludidos en el punto I del apartado de intervenciones urgentes, así como la de las propias bóvedas, una vez medido su grado de humedad, y comprobado que es el idóneo, aunque para alcanzarlo deban ser desprovistas temporalmente de sus actuales revestimientos y sustituir estos por otros de albañilería tradicional, al abrigo de una buena cubierta, sea ésta provisional o definitiva.

5. Es perfectamente factible diseñar una cubierta que cumpla todos los requisitos que se han ido apuntado más arriba, con la mitad de altura de la propuesta por Ventura Rodríguez y por el proyecto actual, si se recurre a otros materiales de cobertura distintos de la teja, resultando en conjunto más tendida y menos visible, lo que no deja de ser otra opción a tener en cuenta.

6. La solución alternativa de una cubierta clásica aterrazada, sin camaranchón visitable, de factible ejecución, conllevaría siempre un mayor peso y la necesidad de restaurar previamente las bóvedas y alcatifas que luego serían inaccesibles por su extradós.

7. El deterioro del intradós de las bóvedas, siempre deberá resolverse desde el interior del templo, con independencia de la solución que se adopte para la cubierta.

8. Las obras de cubiertas, como todas las que se emprendan en el monumento, deberán tener en cuenta, desde el proyecto, y en su caso desde el estudio de seguridad e higiene que corresponda, las protecciones parciales necesarias del monumento y su patrimonio mueble y el ámbito disponible para distribuir los recursos físicos necesarios, contando con la simultaneidad, variedad e importancia social y religiosa de los usos catedralicios, y la vida urbana del entorno inmediato.

\section{B. reseña de documentos específicos consultados}

\section{Diagnóstico Previo. Fases I y 2}

Es en la actualidad un documento inconcluso, que se completará, según manifiestan sus autores, con la tercera y última fase, cuya finalización está prevista para el próximo otoño.

Las fases disponibles son ante todo recopiladoras de datos históricos -textuales y gráficos- en el primer tomo, y datos de materiales, prácticamente dedicado al estudio de la piedra de la construcción, su clasificación, procedencia, datos climáticos, contaminación y dete-
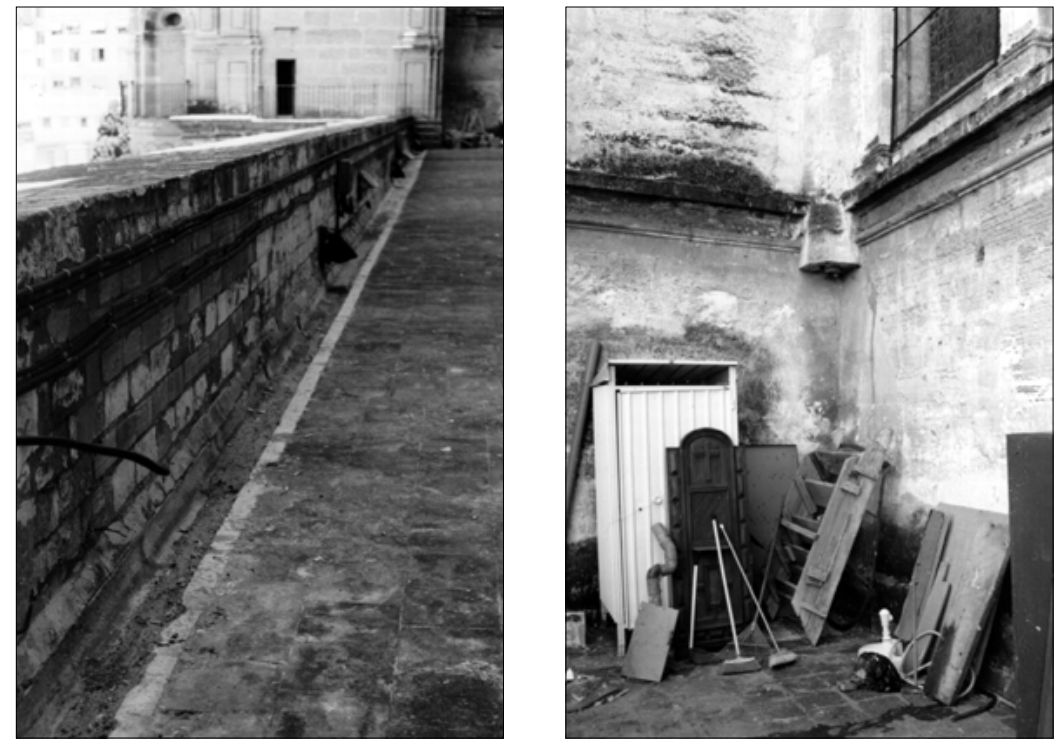

rioro, así como características físico-mecánicas, químicas, etc. más relevantes, complementado con una aportación sobre la naturaleza y soldabilidad de una muestra de acero, y un estudio sobre la naturaleza y biodeterioro de tres muestras de madera. Es de destacar el interés que revisten los datos climáticos y petrológicos para el tema que nos ocupa.

A estos contenidos del segundo tomo anteceden un reportaje fotográfico, tan sólo citado en el índice del ejemplar al que hemos podido acceder, y una propuesta de investigación de la cimentación del edificio y del terreno, cuya planificación y alcance someramente indicados parece acertada. A la vista de la ausencia de patologías relacionables con estos extremos, no se estima urgente su realización por parte de los autores, por lo que su ejecución puede fasearse o diferirse aunque, en nuestra opinión, no debe eliminarse.

Sería deseable que la fase final de este trabajo, además de completar los datos precisos sobre los muchos aspectos no tratados hasta ahora, continuara estableciendo el estado de deterioro (no solo material) del monumento y sus contenidos, marcando las prioridades y sugerencias para su restauración y mantenimiento sostenible, dando con ello pie a la realización del oportuno Plan Director, que en todo caso no debe ignorar los contenidos del trabajo que comentamos.

La llamativa ausencia de planos actuales del monumento en este Diagnóstico Previo, se debe a la contratación independiente de dicho trabajo a la empresa CARTONME, según se explica en el escrito de la Delegación al I.A.P.H.

No nos parece conveniente la disociación radical de estos dos trabajos, que se dan sentido mutuamente, necesitando el primero de los resultados del segundo para apoyar y plasmar las investigaciones que le son propias, y el segundo del primero para enfocar correctamente su contenido, profundidad y extensión.
13. Cubiertas de la nave septentrional de capillas. Cara interior del peto y canal de desagüe.

14. Cubiertas de la nave septentrional de capillas. Desagüe vertical a caño libre. 


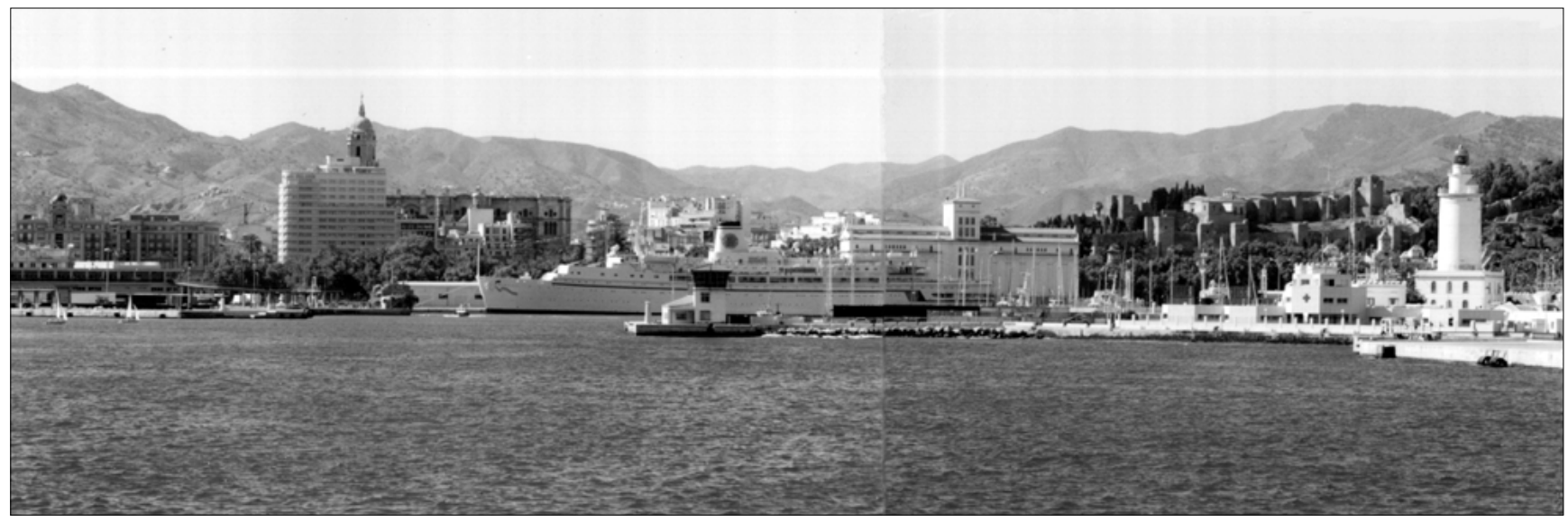

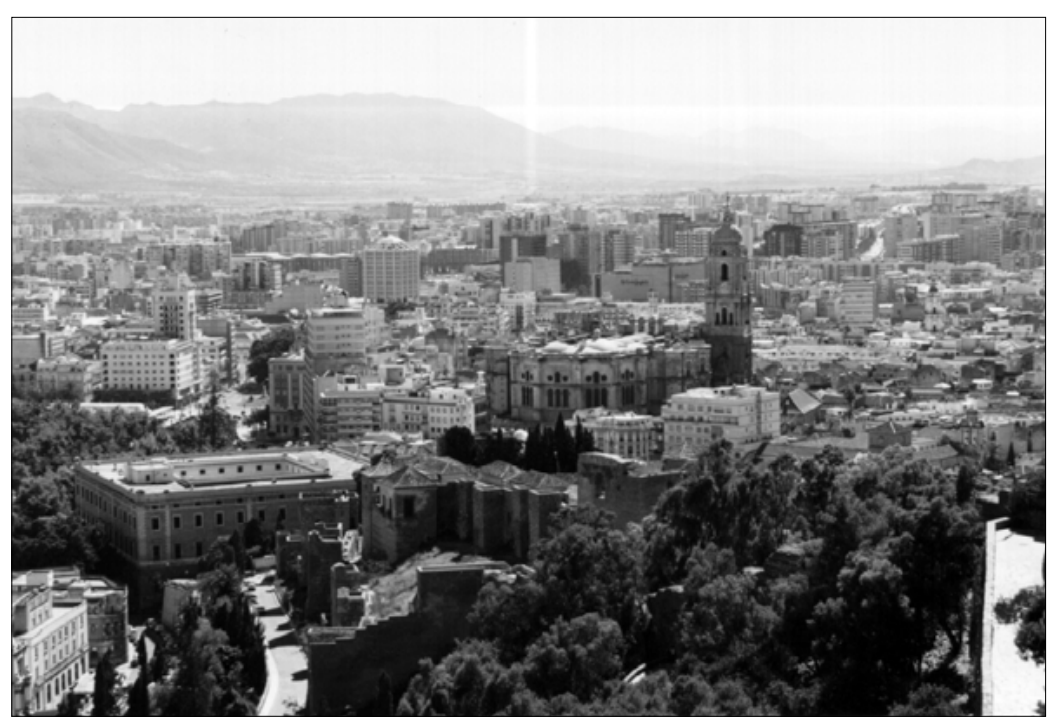

15. La catedral desde el extremo del espigón.

16. La catedral desde Gibralfaro.
Esquemas de drenaje de la Catedral

Han sido cedidos por los autores del citado Diagnóstico Previo, D. Rafael Gómez y D. Tristán Martínez y remitidos el 23 de Junio.

Es éste un trabajo en borrador, avance de posteriores estudios, que efectúa un barrido de los sentidos y puntos de evacuación actuales de las cubiertas, no sólo de las altas, sino de todas las del templo, con indicación de las superficies recogidas en cada uno de ellos, y de la sección mínima necesaria para las conducciones de evacuación correspondiente. Sólo falta compararlas con las realmente existentes y sacar las oportunas conclusiones.

\section{Informe de D. Pedro Salmerón Escobar}

El informe emitido por el arquitecto conservador de las catedrales de Granada y Jaén con fecha de 12 de mayo, es escueto y preciso, abarcando tanto las actuaciones de urgencia que la cubierta necesita como un esquema de estudios previos precisos para garantizar las mejores decisiones sobre los problemas de la Catedral. Incide en la necesidad de hacer converger las iniciativas de las distintas instituciones implicadas, y en el desarrollo urgente del Plan Director de la Catedral de Málaga.
Actuaciones inmediatas en las cubiertas. D. Juan José Jiménez Mata

El arquitecto conservador de la Catedral de Cádiz, en su informe de 8 de mayo pasado, defiende la mejora del funcionamiento de la azotea actual aplicando técnicas tradicionales de albañilería y tratamientos superficiales de impermeabilización mediante lechadas de cal con aceite de linaza. Propone la colocación de una red sobre la cubierta para evitar los perjuicios de las gaviotas y la limpieza y puesta en funcionamiento de la red general de desagües, incluso su compleción, con otros nuevos entre otras cuestiones.

\section{Planimetría actual de la Catedral}

Planimetría de la Catedral de Málaga (sólo hemos podido acceder a una parte de ella consistente en 13 planos de planta, correspondientes a dos series, una con cotas) en soporte informático, facilitada por la empresa adjudicataria, Cartonme, por encargo de la Dirección General de Bienes Culturales de la Consejería de Cultura. Dicha planimetría se ha recibido el día 4 de Julio, estando aún a la espera de que se complemente con los planos de alzados y secciones, y cuantos otros se hayan realizado por la citada empresa hasta el momento.

La importancia de su existencia y de su calidad es evidente para cualquier interpretación e intervención sensata en el edificio. De lo que hemos podido examinar hasta ahora (sólo plantas), cabe decir que parece correcta y adecuada para describir el conjunto catedralicio de modo general, sin entrar en detalles específicos que probablemente no han sido objeto del contrato.

Parece que la documentación gráfica del proyecto de cubiertas comentado, se apoya en esta cartografía, y en él se contienen alzados y secciones cuya factura deja mucho que desear, por la parquedad de detalles decorativos y su modo de representación, especialmente en las bóvedas.

\section{Informe de D. Juan Bassegoda}

Informe del profesor D. Juan Bassegoda Nonell, Dr. Arquitecto, efectuado por encargo del Cabildo Cate- 
dral de Málaga, suscrito el 27 de Junio de 1997, que nos ha sido trasladado el 9 del presente mes de Julio.

Se trata de un texto erudito con referencias bien elegidas en apoyo de la solución de Ventura Rodríguez y de su vigencia actual según el autor, que no entra a enjuiciar la calidad documental y constructiva del proyecto de D. Álvaro Mendiola, del que difiere en la concepción del tablero de cubierta, para el que propone un machihembrado cerámico, de bastante más peso que el proyectado por éste último.

El informe está a favor de acabar la Seo malagueña con unidad de estilo, que es lo que se hace actualmente con el templo de la Sagrada Familia de Barcelona, ejemplo que se cita en el mismo. Creemos que las prioridades son muy distintas en el caso que nos ocupa, y que pueden perfectamente aducirse argumentos en contra, basados en las mismas $u$ otras cartas y normas internacionales de restauración, tanto de lo que el profesor Bassegoda aplica a la terminación actual del templo expiatorio obra de Gaudí, como de lo que defiende hacer en Málaga.

\section{Otros documentos examinados}

- Dossier de prensa facilitado por la Delegación de Málaga de la Consejería de Cultura. Hasta el 4 de julio.

- Resumen de Inversiones de la Consejería de Cultura en la Catedral de Málaga 1989-1997. Departamento de Conservación del Patrimonio Histórico de la Delegación Provincial de la Consejería de Cultura, de 24 de Junio, remitido por la Delegación de Málaga el 4 de julio.

- Plan de Restauración y Ordenación de las Catedrales de Andalucía. Dirección General de BB. AA. Consejería de Cultura. Marzo de 1986, y cuadro-resumen de inversiones, facilitado por la Dirección General de Bienes Culturales el pasado 9 de Julio.

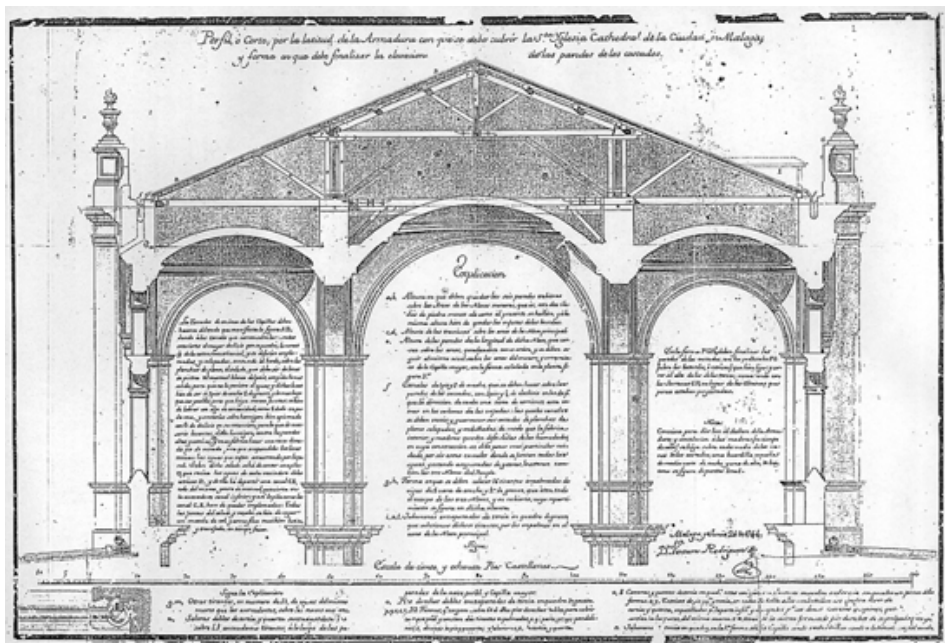

$\varangle$

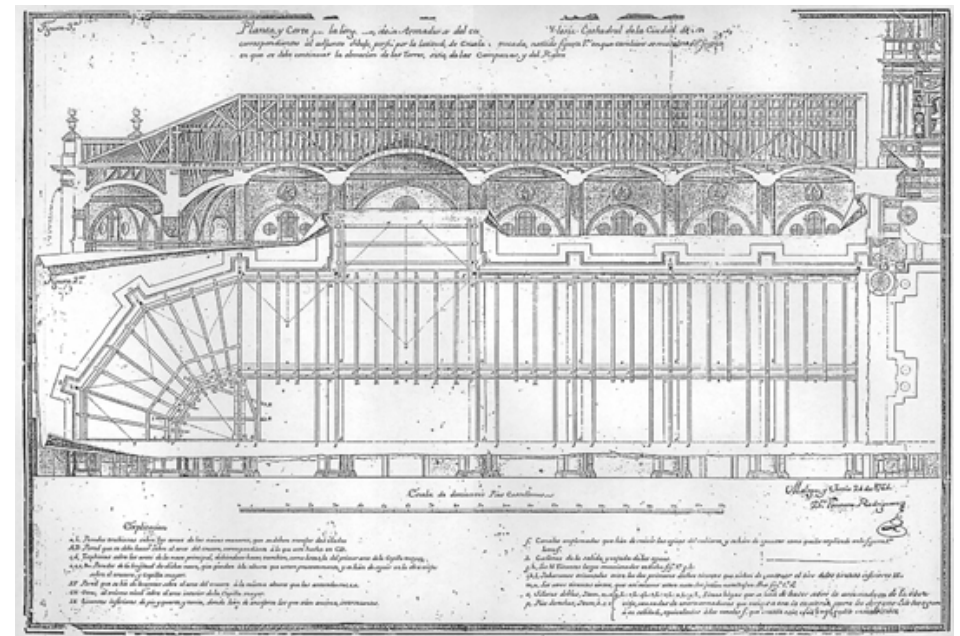

17. Proyectos de cubiertas de Ventura Rodríguez de 1774, sección transversal.

18. Proyectos de cubiertas de Ventura Rodríguez de 1774, semiplanta y sección longitudinales.

\section{Notas}

1. Se dispuso desde el inicio del informe de los documentos siguientes:

- Diagnóstico Previo de la S.I. Catedral de la Encarnación (Málaga), I I y $2^{a}$ fases, redactadas por los arquitectos D. Rafael J. Gómez Martín y D. Tristán Martínez Auladell, por encargo de la Consejería de Cultura. Septiembre de 1996 y febrero de 1997, respectivamente.

- Proyecto de Cubierta de la S.I. Catedral de Málaga. D. Álvaro Mendiola Fernández, arquitecto y D. Fernando Ramos de Rivas, aparejador de fábrica. Incluye copia de dos planos del proyecto de Ventura Rodríguez de 1764.

Otros trabajos e informes fueron recopilándose a medida que se avanzaba en el análisis y están recogidos en el anexo.
2. Es más que probable, que no se tratase solo de trasdosar más, sino de aligerar los muros que recuadran las bóvedas de algunas de las hiladas superiores de los arcos de arranque de las mismas, que en diversos informes se justifican como lo que hoy llamaríamos una precarga para suavizar el tránsito entre los regímenes tensionales y deformatorios de la parte renacentista y la barroca, que defendía Ramos y que tanto se debatieron en su día, siendo uno de los partidarios de su eliminación parcial, el propio Ventura Rodríguez, como puede leerse en los planos de su famosa propuesta de tejado, que ahora se pretende reeditar.

3. Las intervenciones realizadas han sido recogidas del informe de la Delegación Provincial de Málaga. 